Document downloaded from:

http://hdl.handle.net/10251/52996

This paper must be cited as:

Cascales, A.; Laguna, I.; Pérez Lopez, DC.; Perona Ruiz, PD.; Contero, M. (2013). An experience on natural sciences augmented reality contents for preschoolers. Lecture Notes in Computer Science. 8022:103-112. doi:10.1007/978-3-642-39420-1_12.

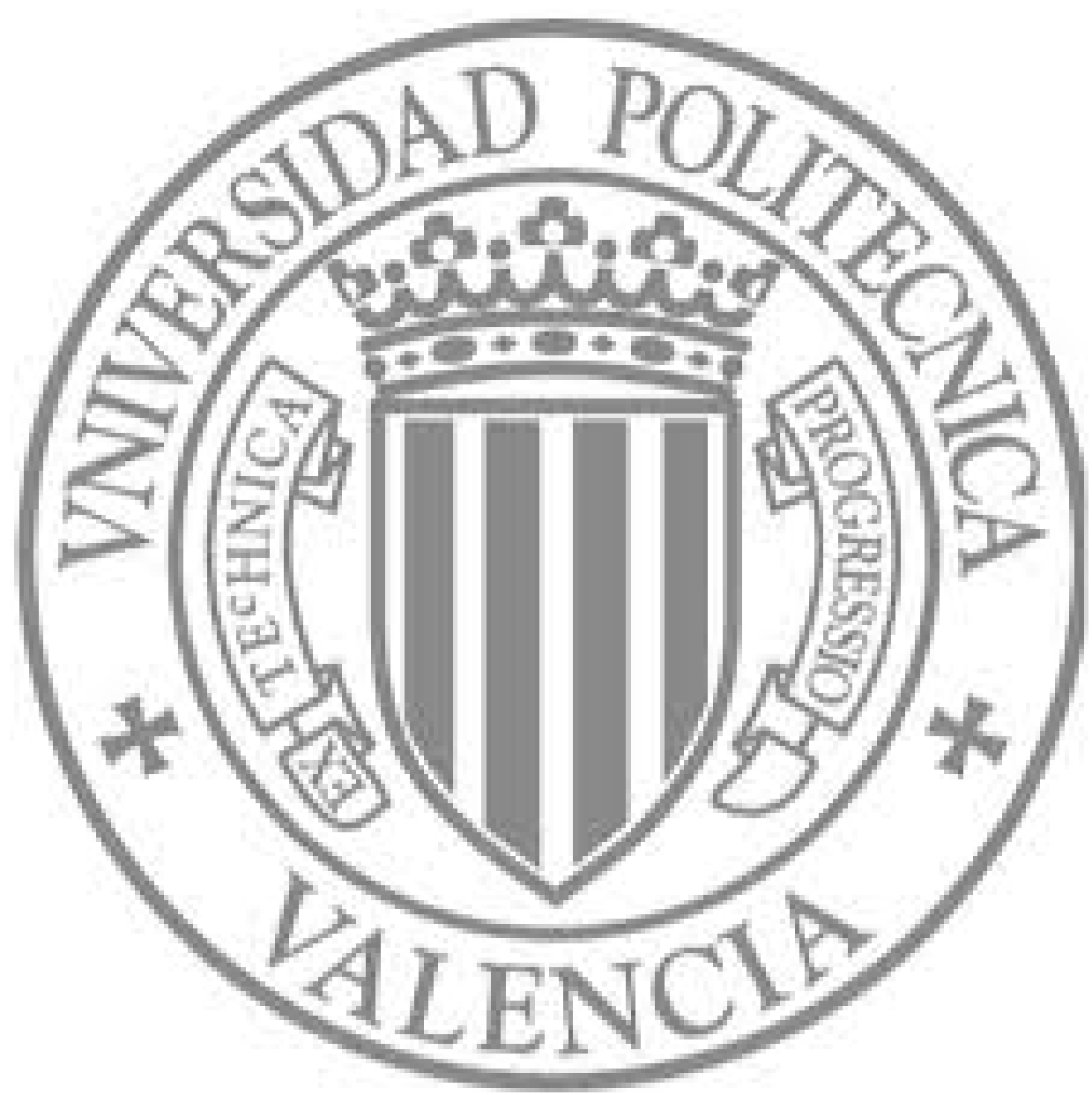

The final publication is available at

http://dx.doi.org/10.1007/978-3-642-39420-1_12

Copyright Springer Verlag (Germany) 


\title{
An Experience on Natural Sciences Augmented Reality Contents for Preschoolers
}

\author{
Antonia Cascales ${ }^{1}$, Isabel Laguna ${ }^{2}$, David Pérez-López ${ }^{3}$, \\ Pascual Perona ${ }^{3}$, and Manuel Contero ${ }^{3}$ \\ ${ }^{1}$ Universidad de Murcia, Avda. Teniente Flomesta 5, 30003 Murcia, Spain \\ antonia.cascales@um.es \\ ${ }^{2}$ Universidad de Alicante, Cra. San Vicente del Raspeig s/n, \\ 03690 San Vicente del Raspeig, Spain \\ isabel. laguna@ua.es \\ ${ }^{3}$ Instituto de Investigación en Bioingeniería y Tecnología Orientada al Ser Humano (I3BH), \\ Universitat Politècnica de València, Camino de Vera s/n, 46022 Valencia, Spain \\ \{dapelo, pperona, mcontero\}@i3bh.es
}

\begin{abstract}
Early education is a key element for the future success of students in the education system. This work analyzes the feasibility of using augmented reality contents with preschool students (four and five years old) as a tool for improving their learning process. A quasi experimental design based on a nonequivalent groups posttest-only design was used. A didactic unit has been developed around the topic "animals" by the participant teachers. The control group followed all the didactic activities defined in the developed didactic materials, while the experimental group was provided in addition with some augmented reality contents. Results show improved learning outcomes in the experimental group with respect to the control group.
\end{abstract}

Keywords: augmented reality, preschool, teaching/learning process.

Early educational intervention [1] has been proposed as an effective tool to fight against poverty and inadequate learning environments, promoting child development and school success. The OECD reports that those students that attended preschool for one year or more scored more than 30 points higher in reading by age 15 in the PISA assessment than those who did not [2].

Educational professionals must be ready for tomorrow's school, facing the constant challenges of our society [3]. In the path of achieving this aim, it is necessary to motivate students, since "learning is more effective when the apprentice voluntarily engages in the process" [3]. Therefore there is a necessity for novel attractive technologies [4] where teachers can provide students efficient and interesting environments to learn [5]. In this context, this work tries to contribute to the improvement of early childhood education by means of the following objectives: 
1. Promote educational innovation by a gradual change in teaching methodology in order to utilize the advantages provided by Augmented Reality (AR).

2. Analyze the possibilities that AR can have on early childhood education.

3. Restructure the classroom environment to incorporate AR

4. Assess improvements that can promote the learning of the students.

Therefore, we have tried to answer the following questions:

- What happens in the teaching and learning process from the use of AR in the classroom?

- How can AR help us to achieve the educational objectives?

- What kinds of interactions are produced when this technology is implemented in the classroom?

In order to answer the previous questions we have developed some augmented reality educational contents and implemented a teaching/learning strategy around them that has been tested on a real preschool scenario.

\subsection{Augmented Reality in Preschool and Kindergarten}

Augmented Reality is a technology which introduces virtual contents such as 3D computer-generated objects, texts and sounds, onto real images and video all in live time. There are different definitions and classifications of AR: Azuma [6] describes $\mathrm{AR}$ as a variation of Virtual Reality (VR), a technology which consists of the complete immersion of a user inside a synthetic environment. In VR the user is not able to perceive the surrounding real world. However, in AR it is possible. In this fact AR differs from VR, because AR adds artificial information to reality while it does not hide the surrounding real world.

Augmented Reality has been touted as one of the most interesting emergent technologies for education, being a powerful and motivating tool which can involve several senses of the student by means of the proper combination of sound, sight and touch. Application of AR technology in education is just beginning to be explored, especially when using it with preschoolers.

One of the first experiences who understood this potential in kindergarten and preschool education was developing a mixed reality platform to provide a tool for collaborative learning [7]. Other studies were conducted in language learning in which AR was used for improving pronunciation and memorization of the Chinese language [5]. Other authors introduced AR educative games to study English as a foreign language $[8,9]$. In these works virtual models and texts in Chinese and English were shown to children in an interactive way controlled by them. Besides, the field of Mathematics was also explored using a serious game to learn Mathematics [10]. Other researchers did not study specifically a subject, instead of it, they studied the learning process. For example, a multisensory mixed reality system was designed for children between 3 and 5 years old that used it in a learning environment formed by images, sounds, and haptic objects [4]. This interactive platform was really helpful to study the advantages of learning through sensorial experiences. Another AR system [11] 
was developed using $\mathrm{AR}$ and robots to deliver positive stimuli to students. In that work, researchers took advantage of an immersive environment to familiarize children with a dramatic activity. Finally, other authors provided an AR tool for an interactive storyteller to enhance children reading [12].

As it could be deducted in the last paragraphs, AR contributes in many ways to support the teaching/learning process: students' senses are involved in interactive activities by using manipulative material [7]. Besides, self-learning is promoted by enjoyable edutainment in friendly interfaces [5, 8]. And from the point of view of technology approval, in previous studies it is shown that students and their parents have made positive valuations about AR [13].

In the next sections, a detailed description of the didactic contents is provided, after a short introduction about AR in educational contexts. Then, the experimental design is presented, followed by the results, discussion and conclusions.

\section{Materials and Methods}

\subsection{Didactic Materials}

The augmented reality application consists of a launcher, a camera configuration tool and a content installation tool. The launcher is designed to manage a collection of AR contents and it allows the user to launch a specific AR application, selecting its academic year, subject and language through pull-down menus as seen in figure 1-a. It also provides a preview of the content; a handbook about it and the AR marker which has to be printed in order to use the AR application (see figure 1-b).
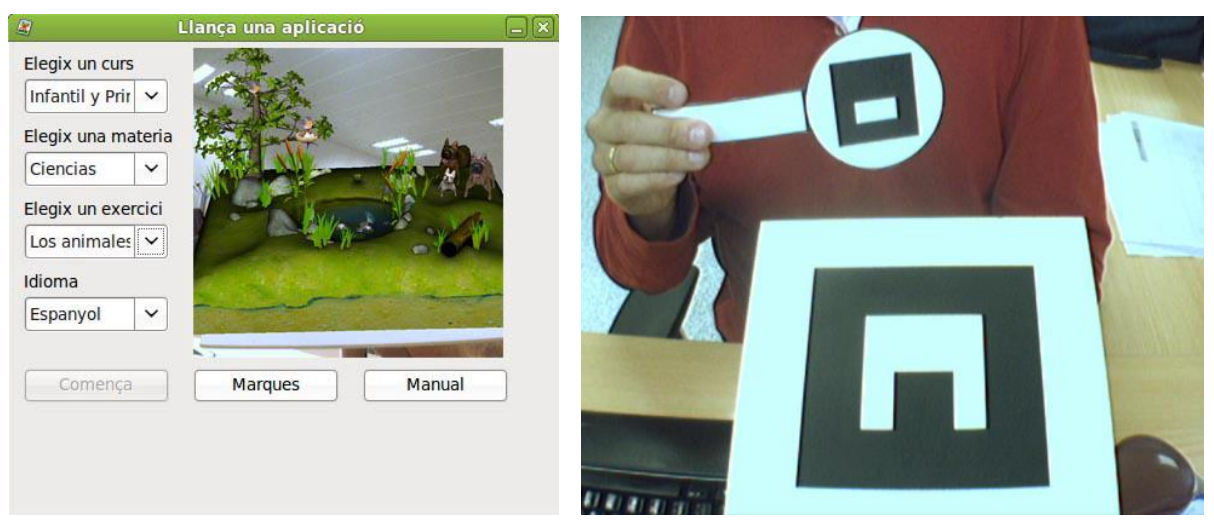

Fig. 1. (a) Launcher to run the AR animal application; (b) AR marks used by the application

The camera configuration tool allows the user to configure video modes, exposition, color and tracking parameters. Finally, the installation tool allows installing and uninstalling AR contents from a local drive or from a URL. All these elements are expected to be used by the teacher, who launches the selected content for the preschoolers. 


\subsection{Application Structure}

The application, like other AR ones, follows the "magic mirror" paradigm, where a computer monitor shows a live video stream from a webcam, and renders some 3D models over the AR markers. The application shows a set of icons at the top right side of the screen, providing some common functionality as seen in figure 2. The AR marker has been provided with a special handle to be used more comfortably by preschoolers, as can be seen in figure 3-a. The AR application incorporates some interface elements to access much more information, and to control certain simulation parameters. They are common tools, such as changing the zoom level of the 3D model that appears on the AR mark, which can be accessed using the mouse. Other common tools are the audio switch on/off, to show the application user guide, to quit the application and to display a context-sensitive help on the action being performed at any moment. In addition, it is worth mentioning a functionality that has proved to be very useful for the teachers. It is the possibility of stopping the tracking of the AR marker. This functionality allows freezing the position of the 3D model on the screen, without holding the AR marker. This feature is very useful when a teacher wants to point to a part of the model with their hands, for example, if the AR application is visualized on a digital whiteboard.

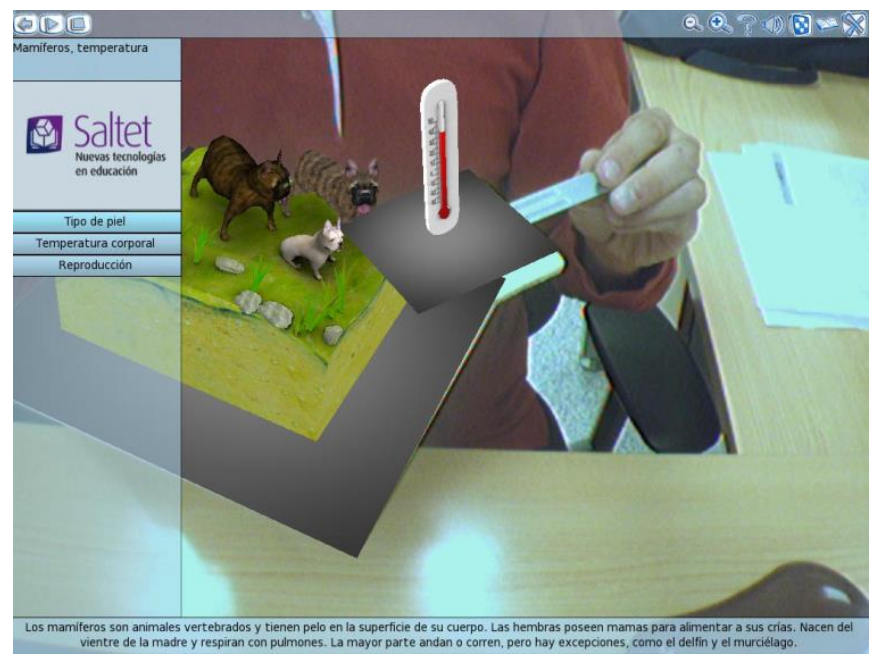

Fig. 2. Interface characteristics. Example of secondary mark acting as a thermometer

The system also includes buttons to control an auditory narrative, (play, pause and stop) at the top left part of the screen. And finally, close to those buttons, there is a button used to return to the previous screen. Moreover, the left side of the screen is reserved to include menus that dynamically change. In this way, these menus can give access to different activities, "Presentation" and "Lesson", as presented below. Also, under these menus, there is a rectangular area reserved to show informative texts relative to the visualized scene. Under this area, there is a small square which is used to show 2D images which can produce a better content visualization. Finally, in the low- 
er side of the screen, there is also another rectangle reserved to show more detailed explanations in text format. Note that those explanations are also shown as an auditory narrative. And also note that this text box incorporates an automatic scroll to support long texts.

It should be noted that the system can be run in several languages by using XML configuration files, so the system loads these files which contain links to all the digital resources such as 3D models, texts and audio. These resources are organized in language folders, so, the way to change the language is to load a different set of digital resources from the right language folder. The system provides that option by a dropdown menu in the launcher.

\subsection{AR Animals Application}

This AR application provides two activities, "Presentation" and "Lesson", and it includes an innovative solution in AR. That solution is a special magnifying glass, which will be described below. The main objective of this application is to help the teachers to show the students the vertebrate animal classification and to show in detail these animals' coats, kind of reproduction and corporal temperature. Thus, "Presentation" shows, over the AR marker, a kind of park where five animated couples of animals appear. This mode only allows the user to observe the scene; there is no more interaction than moving the $\mathrm{AR}$ marker and to observe the animals from different points of view.
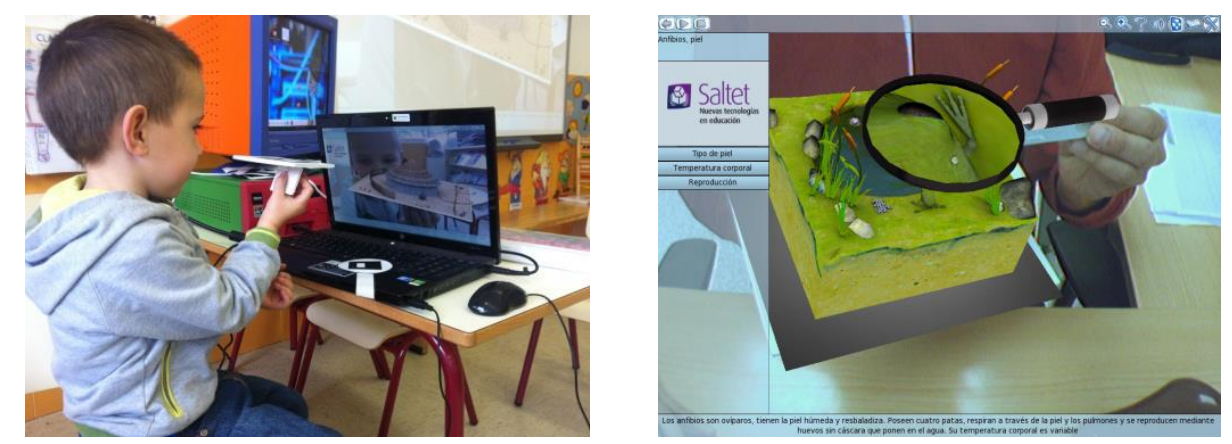

Fig. 3. (a) Preschooler using the AR application (b) Two marks interaction: magnifying glass

The second activity, "Lesson", shows the same park over the AR marker and explains the vertebrate animal classification using different texts and auditory explanations. Thus, this section is composed of five sub-activities which can be accessed by a set of buttons located at the left of the screen: "Mammals", "Birds", "Fishes", "Amphibians" and "Reptiles". Each sub-activity presents a male and a female of each kind of animal over the AR marker, and three buttons; "Coat", "Corporal temperature" and "Reproduction". These buttons activate an operating mode where two AR marks can be used at the same time. A big mark is used to represent 3D models, and a small one to represent a magnifying glass or a thermometer, depending on the user selection. So, 
the thermometer shows hot, cold or variable temperature when the user moves the small mark closer to the big one, that is, when the thermometer is over the animal as seen in Figure 2.

In order to control the user interaction with the two marks, the system calculates the distance between the 3D models and the small mark, and defines some distance thresholds, so, when these thresholds are exceeded an event occurs. The magnifying glass works as is expected, that is, it applies a zoom to the animals, hence, when the user looks at the virtual glass, he obtains an augmented vision through that glass, like a real magnifying glass, as can be seen in figure 2 . In this way, the user can observe coat details and how the animals reproduce. In order to do this, a 3D transformation between the markers is calculated by the system and it is applied to a shader, which is also applied to the glass. The idea is to look at the big mark from the small one's point of view, and to apply some zoom.

It is important to mention that those augmented reality resources were initially designed for primary school students, but after a preliminary evaluation with preschoolers, it was observed that they were able to access the basic functionality of the application without any problem.

\subsection{Libraries}

This system was conceived and developed to be run under Ubuntu Lucid Lynx (10.04), however, it can be run under Windows. The system was developed using OGRE as the graphics engine and a set of public libraries like OIS to manage input devices, Audiere to manage sound streams, tinyXML to manage XML configuration files, v412 to capture video from a webcam under Linux, MyGUI to develop the graphical user interface and OpenCV to develop our own AR engine under Linux.

In order to support the development of AR applications, our research group has developed its own software library [14]. Although there are several public libraries with AR capabilities, we decided to develop it in order to overcome some drawbacks present in some public libraries (jitter, bad performance under illumination variations, lack of support of infrared markers, etc.).

\subsection{Participants}

The research involved two groups of eighteen preschoolers in each group, with ages between four and five years from the public school Virgen de los Desamparados in Orihuela (Spain). One group was taken as the control group, while the other was taken as the experimental group. Both groups were composed of third graders from the second cycle of pre-primary education, according to the Spanish education system. Both groups had the same teachers.

The school is located in a rural area. It is one of the seventeen pilot technological schools in the province of Alicante (Spain). The school is fully equipped with technology and also has formed a team of teachers experienced in ICT, which works hard to improve the use of ICT in the classroom. Regarding the students participating in our research, they have been using ICT in the school since they were three years old. 
Table 1. Students' categorical estimation scale

\begin{tabular}{|c|c|c|c|}
\hline \multirow{2}{*}{$\begin{array}{l}\text { Pupil: } \\
\text { Item } \\
\end{array}$} & \multicolumn{3}{|c|}{$\begin{array}{l}\text { NA- Not Achieved } \\
\text { IP- In progress } \\
\text { A- Achieved }\end{array}$} \\
\hline & \multicolumn{3}{|c|}{ Criteria } \\
\hline Animals & & & \\
\hline $\begin{array}{l}\text { - Child recognizes vertebrate animals: dog } \\
\text { - Child recognizes invertebrate animals: caterpillar } \\
\text { - } \quad \text { Child recognizes mammals } \\
\text { - } \quad \text { Child recognizes birds } \\
\text { - Child recognizes fish } \\
\text { - Child recognizes amphibians } \\
\end{array}$ & $\begin{array}{l}\text { NA } \\
\text { NA } \\
\text { NA } \\
\text { NA } \\
\text { NA } \\
\text { NA }\end{array}$ & $\begin{array}{l}\text { IP } \\
\text { IP } \\
\text { IP } \\
\text { IP } \\
\text { IP } \\
\text { IP }\end{array}$ & $\begin{array}{l}\text { A } \\
\text { A } \\
\text { A } \\
\text { A } \\
\text { A } \\
\text { A }\end{array}$ \\
\hline \multicolumn{4}{|l|}{ Knowledge about mammals: } \\
\hline $\begin{array}{l}\text { - Mammals are born from the womb } \\
\text { - Mammals nurse their young with milk } \\
\text { - Mammals have hair } \\
\text { - Some mammals are terrestrial } \\
\text { - Some mammals are aquatic } \\
\text { - Some mammals can fly } \\
\end{array}$ & $\begin{array}{l}\text { NA } \\
\text { NA } \\
\text { NA } \\
\text { NA } \\
\text { NA } \\
\text { NA }\end{array}$ & $\begin{array}{l}\text { IP } \\
\text { IP } \\
\text { IP } \\
\text { IP } \\
\text { IP } \\
\text { IP }\end{array}$ & $\begin{array}{l}\mathrm{A} \\
\mathrm{A} \\
\mathrm{A} \\
\mathrm{A} \\
\mathrm{A} \\
\mathrm{A}\end{array}$ \\
\hline \multicolumn{4}{|l|}{ Knowledge about birds: } \\
\hline $\begin{array}{l}\text { - } \quad \text { Birds are born from eggs } \\
\text { - } \text { Birds do not nurse their young with milk } \\
\text { - } \text { Birds have feathers } \\
\text { - Usually birds can fly } \\
\text { - } \quad \text { Some birds live on earth } \\
\end{array}$ & $\begin{array}{l}\text { NA } \\
\text { NA } \\
\text { NA } \\
\text { NA } \\
\text { NA }\end{array}$ & $\begin{array}{l}\text { IP } \\
\text { IP } \\
\text { IP } \\
\text { IP } \\
\text { IP }\end{array}$ & $\begin{array}{l}\text { A } \\
\text { A } \\
\text { A } \\
\text { A } \\
\text { A }\end{array}$ \\
\hline \multicolumn{4}{|l|}{ Knowledge about fish: } \\
\hline $\begin{array}{l}\text { - Fish hatch from eggs } \\
\text { - Fish have scales } \\
\text { - Fish breathe through gills }\end{array}$ & $\begin{array}{l}\text { NA } \\
\text { NA } \\
\text { NA }\end{array}$ & $\begin{array}{l}\text { IP } \\
\text { IP } \\
\text { IP }\end{array}$ & $\begin{array}{l}\text { A } \\
\text { A } \\
\text { A }\end{array}$ \\
\hline \multicolumn{4}{|l|}{ Knowledge about amphibians: } \\
\hline $\begin{array}{l}\text { - Amphibians hatch from eggs } \\
\text { - When amphibians are immature they breathe through gills } \\
\text { - When amphibians are adults they live on land and water }\end{array}$ & $\begin{array}{l}\text { NA } \\
\text { NA } \\
\text { NA }\end{array}$ & $\begin{array}{l}\text { IP } \\
\text { IP } \\
\text { IP }\end{array}$ & $\begin{array}{l}\text { A } \\
\text { A } \\
\text { A }\end{array}$ \\
\hline
\end{tabular}

Students often work with technology in their own classrooms, where they have several computers and an interactive whiteboard.

\subsection{Experimental design and method}

In this research a nonequivalent group posttest-only [15] design has been chosen. Under this scheme, one group (the experimental group) received the intervention (augmented reality contents), while the other group (the control group) does not use AR. The intervention was done in a natural situation, without a random selection of groups [16].

Initial conditions for both groups were similar: each group was composed by 18 children between 4 and 5 years old. Moreover, both groups had had the same teachers in the previous year and they had also studied the same contents.

Besides, this experience has been developed using an active and communicative methodology. On the one hand, teachers were deeply implied providing feedback data 
about student experiences. On the other hand, preschool students worked properly following the didactic guides developed by participant teachers. The chosen didactic unit for the two groups involved was "animals". Two versions of these didactic materials were created. The only difference between them was that the "experimental unit" provided the augmented reality resources described in the previous section. In this way both units have the same educational curriculum content, one with AR and one without it. Therefore the independent variable of this research was the presence of Augmented Reality as a didactic tool.

The assessment of experimental and control groups was performed using an evaluative categorical scale completed by teachers (see Table 1). This scale consisted of 22 items, where each item was checked according to the following categories: A (Achieved), IP (In Progress) and NA (Not Achieved).

\section{Results}

Table 2 summarizes the results obtained from applying the categorical estimation scale presented in Table 1. Experimental group reflects a slight improvement with respect to control group although there is no statistical significant difference.

Table 2. Results of learning outcomes in didactic unit "animals" (absolute frequencies)

\begin{tabular}{lcccccc}
\hline & \multicolumn{3}{c}{ Control Group } & \multicolumn{4}{c}{ Experimental Group } \\
& A & IP & NA & A & IP & NA \\
\hline Classification of animals: & 11 & 5 & 2 & 13 & 4 & 1 \\
Mammals & 11 & 5 & 2 & 13 & 3 & 1 \\
Birds & 9 & 5 & 4 & 13 & 4 & 1 \\
Amphibians & 10 & 5 & 3 & 12 & 5 & 1 \\
Fish & 13 & 4 & 1 & 15 & 3 & - \\
\hline Characteristics of animals & 12 & 5 & 1 & 15 & 3 & - \\
\hline Body parts of animals & & & & & & \\
\hline
\end{tabular}

\section{Discussion and Conclusions}

The slight improvement that results reflect must be put in context. Augmented reality contents are one of the ingredients of the didactic activities designed to support this learning unit. The learning process was organized around team work, and AR contents were used by the preschoolers at their own pace. AR contents served as a catalyst providing a real motivation and stimulus for the children, and teachers observed a very positive impact on students.

Participant teachers had no previous exposure to this technology, but it was easily integrated in the class dynamics. The perception of participant teachers was that aug- 
mented reality improved learning activities, supporting students' constructive learning approach. Teachers considered AR to be a resource that is tailored to the characteristics of their students and thus is useful for learning.

All study participants considered that the use of AR is a good tool in the teachinglearning process. The conclusions we reached in our experience of inclusion of AR as a part of the teaching-learning process are the following:

- The use of AR promotes active behavior in the student.

- The work of teaching improves with the use of AR. Daily work is more playful and fun for both students and teachers.

- Students learn more when they are using AR and they achieve more learning goals than if they are not using AR.

- AR also promotes communication skills, promoting all kinds of interactions in the classroom between teacher and students, students and students, students and families, families and families and teachers and teachers.

The experience with the use of AR has been very positive for teachers and students. After the results obtained with the use of AR, participant teachers will motivate their colleagues to use AR in their classrooms. Finally, teachers are in full agreement with the resource and its viability of application. They considered feasibility, time spent on the implementation, distribution of content and resources and infrastructure available, appropriate and sufficient.

Acknowledgements. The Spanish Ministry Economy and Competitiveness partially supported this work (Project ref. TIN2010-21296-C02-01).

\section{References}

1. Barnett, W. S.: Effectiveness of Early Educational Intervention. Science. 333(6045), 975978 (2011)

2. OECD: Investing in high-quality early childhood education and care (ECEC). OECD Publishing. Retrieved from http://www.oecd.org/dataoecd/0/28/48980282.pdf

3. Campos, P., Pessanha, S.: Designing Augmented Reality Tangible Interfaces for Kindergarten Children. In: Shumaker R. (ed.) 2011 International Conference on Virtual and Mixed Reality. LNCS, vol. 6773, pp. 12-19). Springer, Berlin (2011)

4. Lim, J., Kim, S.: A Study on Markerless AR-based Infant Education System using CBIR. Communications in Computer and Information Science. 78, 52-58 (2010)

5. Chen, C.H., Su, C.C., Lee, P.Y., Wu, F.G.: Augmented Interface for Children Chinese Learning Technologies. In: $7^{\text {th }}$ IEEE International Conference on Advanced Learning Technologies, pp. 268-270. IEEE Press, New York (2007)

6. Azuma, R.: A Survey of Augmented Reality. Presence: Teleoperators and Virtual Environments, $6(1), 355-385$ (1997)

7. Winkler, T., Herczeg, M., Kritzenberger, H.: Mixed Reality Environments as Collaborative and Constructive Learning Spaces for Elementary School Children. In: Barker, P., Rebelsky S. (eds.) Proceedings of World Conference on Educational Multimedia, Hypermedia and Telecommunications 2002, pp. 1034-1039. AACE, Chesapeake (2002) 
8. Hsieh, M. C., Lee, J. S.: AR Marker Capacity Increasing for Kindergarten English Learning. In: International MultiConference of Engineers and Computer Scientists, vol. 1, pp. 663-666 (2008)

9. Hsieh, M. C., Lin, H. C. K.: Interaction Design Based on Augmented Reality Technologies for English Vocabulary Learning. In: Wong S.L. et al. (eds.) Proceedings of the 18th International Conference on Computers in Education, vol. 1, pp. 663-666. Asia-Pacific Society for Computers in Education (2010)

10. Lee, H., Lee, J.: Mathematical Education Game Based on Augmented Reality. Technologies for E-Learning and Digital Entertainment, 442-450 (2008)

11. Hyun, E., Choi, K., Kim, G. J., Han, J., Jo, M., \& Kim, N.: Delphi Survey on the Use of Robot Projector based Augmented Reality in Dramatic Activity for Young Children. International Journal of Digital Content Technology and its Applications, 5(11), 272-282 (2011)

12. Kim, H.M, Song, T.H., Jung, S.M., Kwon K.H., Jeon, J.W.: Virtual Storyteller Using Marker Based AR and FPGA. In: IEEE $54^{\text {th }}$ International Midwest Symposium on Circuits and Systems, pp. 1-4. IEEE Press, New York (2011)

13. Dunleavy, M., Dede, C., Mitchell, R.: Affordances and Limitations of Immersive Participatory Augmented Reality Simulations for Teaching and Learning. Journal of Science Education and Technology, 18, 7-22 (2009)

14. Martín-Gutiérrez, J., Saorín, J.L., Contero, M., Alcañiz, M., Pérez-López, D., Ortega, M.: Design and validation of an augmented book for spatial abilities development in engineering students. Computers \& Graphics. 34(1), 77-91 (2010)

15. Cook, T.D., Campbell, D.T., Day, A.: Quasi-experimentation: Design and Analysis Issues for Field Settings, pp. 19-21. Houghton Mifflin, Boston (1979)

16. Buendía, L., Colás, P., Hernández-Pina, F.: Métodos de Investigación en Psicopedagogía. McGraw Hill, Madrid (1997) 